\title{
Delay in Making Decision to Seeking Care on Institutional Delivery and Associated Factors Among Mothers Who Gave Birth in South Gondar Zone Hospitals,2020. A Cross-sectional Study
}

Gebrehiwot Ayalew Tiruneh ( $\nabla$ tirunehgebrehiwot@gmail.com )

Debre Tabor University

Dawit Tiruneh Arega

Debre Tabor University

Bekalu Getnet Kassa

Debre Tabor University

Keralem Anteneh Bishaw

Debre Markos University

Research

Keywords: Seeking Care, Ethiopia, Factors, Institution

Posted Date: April 6th, 2021

DOl: https://doi.org/10.21203/rs.3.rs-349973/v1

License: (c) (i) This work is licensed under a Creative Commons Attribution 4.0 International License.

Read Full License 


\section{Abstract}

Background: Delay to making decision to seeking care contributes to high maternal mortality and morbidity in developing countries. Major factor that contribute to maternal death in developing countries is decision-making to seek care. This study aimed at assessing the prevalence and associated factors of delay in making decision to seeking care on institutional delivery among mothers who gave birth in South Gondar zone hospitals, Ethiopia, 2020.

Methods: An institution-based cross-sectional study design was conducted from September1October30/2020 with 650 mothers were participated in this study using a systematic random sampling technique. Data were collected using a face-to-face interview with pretested semi-structured questionnaires Bi-variable and multi-variable analyses conducted and the Odds ratio with $95 \% \mathrm{Cl}$ was estimated to identify factors of delay to making decision to seeking care. The statistical significance was declared at $\mathrm{p}<0.05$.

Results: Delay in making decision to seeking care on institutional delivery was found to be $36.3 \%$ $(95 \% \mathrm{Cl}=32.6$ to 40.1$)$. The mean age of the respondents was 27.23 with a standard deviation of 5.67 . Mothers who reside in rural area ( $A O R=3.14,95 \%, C l: 2.40-4.01)$, uneducated mothers ( $A O R=3.62,95 \%$, Cl:2.45-5.52), unplanned of pregnancy (AOR: 2.01, 95\% Cl: 1.84-7.96), and no health facilities in Keble (AOR: $1.62,95 \% \mathrm{Cl}: 1.43-6.32$ ) were statistically associated with delay to making decision to seeking care.

Conclusion: One in three delivered mothers had been delayed in making decision to seek care in South Gondar zone. Pregnant mothers living in the rural area, unplanned of pregnancy, uneducated mothers, no health facilities in Keble Therefore, strategies to identify determinants and reduced of delay in making decision to seek care.

\section{Plain English Summary}

Delay to making decision to seeking care contributes to high maternal mortality and morbidity in developing countries. The time interval from the first onset of labour to decision to seek emergency obstetric care from health facility and time longer than the expected time (one hour) is considered as first delay. Different study in the world, sub-Saharan Africa and Ethiopia showed that mothers who have experienced delay in making decision to seeking care have faced a number of health problems for both the mother and neonate. An institution-based cross-sectional study design was conducted from September1-October30/2020 with 650 mothers were participated in this study using a systematic random sampling technique. Data were collected using a face-to-face interview with pretested semistructured questionnaires Bi-variable and multi-variable analyses conducted and the Odds ratio with $95 \%$ $\mathrm{Cl}$ was estimated to identify factors of delay to making decision to seeking care. So that delay in making decision to seeking care on institutional delivery was found to be high. The mean age of the respondents was 27.23 with a standard deviation of 5.67. One in three delivered mothers had been delayed in making decision to seek care in South Gondar zone. Pregnant mothers living in the rural area, unplanned of 
pregnancy, uneducated mothers, no health facilities in Keble Therefore, strategies to identify determinants and reduced of delay in making decision to seek care.

\section{Introduction}

Delay in making decision to seeking care on institutional delivery refer to the time to deciding to seek emergency care which is happen at the family unit and community level and reflect in deciding to seek care for pregnancy complications[1-3]

Globally, maternal mortality and morbidity are an alarming public health issue and devastating effect on their children, her family, and her community $[1,2]$

Different study in the world, sub-Saharan Africa and Ethiopia showed that mothers who have experienced delay in making decision to seeking care have faced a number of health problems for both the mother and neonate such as antepartum hemorrhage, premature rupture of membrane, postpartum hemorrhage, uterine rupture[4-7].

Several factors have been identified as barriers to pregnant mothers including access to early and competent care with skilled birth attendants, optimally in a health facility. Research reports that factors associated with women not seeking health facility care include perceived inequality of care received, an inadequate number of skilled health professionals, geographical inaccessibility, and disrespectful service delivery by health care providers. Factors related to accessing skilled health care include a woman's awareness of pregnancy danger signs that require emergent and competent health care management. Women who do not have autonomous decisions making concerning their health care additionally are challenged by family restricting access to timely emergency maternity care $[6,8-12]$.

\section{Method}

\section{Study design and period}

Health facility-based cross-sectional study was conducted from September 1 to October 30/ 2020G.C in South Gondar zone hospitals, Northwest Ethiopia.

\section{Study area}

The study was conducted in the South Gondar zone hospitals located in the Amhara Region, Northwest, Ethiopia. Debre Tabor is the capital city of the zone which is found 103kilometers away from Bahir Dar (the capital city of Amhara Regional State) and about 667 Kilometers away from Addis Ababa (the capital city of Ethiopia). According to a report from the south Gondar zone administrative office, the population of this zone is $2,609,823$. Females number 1304,911 in this zone, With the majority who are economically dependent on agriculture. There is one Referral Hospital and seven additional governmental 
hospitals (Mekane-Eyesus, Andabet, Nifas-Mewucha, Addis-Zemen, Tach Gait, Wogeda, and Event). The zone has 96 public health centers, 140 private clinics, and 403 health posts.

\section{Source population}

All mothers who gave birth in South Gondar zone governmental hospitals in 2020.

\section{Study population}

All mothers who gave birth in South Gondar zone selected hospitals during a data collection period.

\section{Inclusion criteria}

All mothers who gave birth among selected hospitals and resided in the study area.

\section{Exclusion criteria}

Mothers who were admitted before the onset of labor for follow up in the waiting room.

Mothers who were not living in the study area for less than six months.

\section{Study variables}

Dependent variable: Delay in making decision to seeking care on institutional delivery

Independent variables: socio-demographic characteristics; age, residence, marital status, ethnicity, religion, education of the mother, education of husband, occupation of the mother, occupation of husband, family income. Obstetrics related factors; gravidity, parity, ANC follow up, type of pregnancy, mode of delivery in the past, the current mode of delivery. Health facility factors: available health facility, the distance of health facility, means of transportation, previous pregnancy birthplace, know any danger signs of labor, and decision-maker for EOC[13, 14].

\section{Operational definition}

Institutional delivery utilization: when a mother gave birth at a health.

Delays of the decision to seeking care: refers to the time taken greater than one hour to decision seek care after the onset of labor[14].

\section{Sample size determination}

The sample size was determining using a single population proportion formula by using the following assumptions: the proportion of delay in making decision to seeking care was $26.2 \%$ [7], $5 \%$ margin of error and $10 \%$ non-response rate and design effect of 2 with the final required minimum sample size estimated to be 653 . 


\section{Sampling Procedure and Technique}

The total sample size was proportionally allocated for five randomly chosen hospitals as a cluster from eight hospitals in the south Gondar zone. For each hospital, the first participant selected randomly; then, the subsequent participants were selected by a systematic sampling technique every two interval for each hospital.

\section{Data collection techniques}

The data were collected through face -to- face interview with postpartum mothers in private room before discharge. Five diploma Midwives for data collection and two Midwifery professionals for supervision were recruited. The questionnaires were prepared in English, and then translated to Amharic (local language) for simplicity and back to English to maintain consistency of the tool.

\section{Data quality assurance}

The questionnaire was pretested to check participant response, language clarity, and appropriateness of the questionnaires. A pretest was conducted on $5 \%$ out of the study area called koladiba hospital. At the end of the pretest, ambiguous and culturally sensitive questions were amended, clarified adjusted before data collection began. One-day training was given for data collectors and supervisors to clarify the purpose of the study and techniques of data collection. The collected data were checked daily for its completeness and consistence. The collected data were kept locked in a file cabinet accessible only for the researchers.

\section{Data Processing, Analysis, and Interpretation}

The data were coded and entered into Epi-data version 3.1. Then it was exported to Statistical Package of Social Science (SPSS) version 20.00 for data checking, cleaning, and analysis. Descriptive statistics were performed on numerical value, frequencies, mean, proportion to describe the study population about dependent and independent variables. The results of the study were presented in the text, and tables. Binary logistic regression was used to identify statistically significant independent variables, and independent variables having a p-value of less than 0.2 were entered to multivariable logistic regression for further analysis and to adjust for confounding variables. The Adjusted Odds Ratio (AOR) was used to identify determinant variables for delays to institutional delivery service with $95 \%$ confidence interval at Pvalue $<0.05$

\section{Results}

Socio-Demographic Characteristics of the Respondents: A total of 650 mothers participated in the study with a response rate of $99.54 \%$. About $78.6 \%$ were found in the age group $20-34$ years. Around $34.5 \%$ of participants were living in the rural area, and $96.8 \%$ were orthodox Christianity religion followers. Of the study participants, $20.6 \%$ were housewives. From the participants, $29.4 \%$ unable to read and write, and $37.5 \%$ husbands of the respondents had college and above educational levels (Table 1 ). 
Table 1

Socio-demographic characteristics for delay in making decision to seeking care on institutional delivery service among mothers who gave birth in South Gondar zone hospitals, Ethiopia, 2020.

\begin{tabular}{|c|c|c|c|}
\hline Variables & Categories & Frequency & Percent(\%) \\
\hline \multirow[t]{3}{*}{ Age of the mothers (years) } & $<20$ & 85 & 13.1 \\
\hline & $20-34$ & 511 & 78.6 \\
\hline & $\geq 35$ & 54 & 8.3 \\
\hline \multirow[t]{2}{*}{ Residence } & Urban & 426 & 65.5 \\
\hline & Rural & 224 & 34.5 \\
\hline \multirow[t]{2}{*}{ Marital status of the mothers } & Married & 644 & 99.1 \\
\hline & Others ${ }^{*}$ & 6 & 0.9 \\
\hline \multirow[t]{3}{*}{ Religion } & Orthodox & 629 & 96.8 \\
\hline & Muslims & 19 & 2.9 \\
\hline & protestant & 2 & 0.3 \\
\hline \multirow[t]{4}{*}{ Education of the mothers } & unable to read and write & 191 & 29.4 \\
\hline & Grade $1-8$ & 181 & 27.8 \\
\hline & Grade9-12 & 103 & 15.8 \\
\hline & College and above & 175 & 26.9 \\
\hline \multirow[t]{6}{*}{ Occupation status of the mothers } & Housewife & 134 & 20.6 \\
\hline & Employed & 314 & 48.3 \\
\hline & Merchant & 77 & 11.8 \\
\hline & Student & 33 & 5.1 \\
\hline & Farmer & 55 & 8.5 \\
\hline & Daily labor & 37 & 5.7 \\
\hline \multirow[t]{4}{*}{ Education of husband } & Unable to read and write & 140 & 21.5 \\
\hline & Grade 1-8 & 183 & 28.3 \\
\hline & Grade9-12 & 40 & 12.3 \\
\hline & College and above & 244 & 37.5 \\
\hline
\end{tabular}

*: single and divorced, **: Muslim and protestant 


\begin{tabular}{|llll|}
\hline Variables & Categories & Frequency & Percent(\%) \\
\hline Occupation of husband $(\mathrm{n}=647)$ & Employed & 202 & 33.6 \\
& Merchant & 181 & 28.7 \\
& Student & 43 & 6.6 \\
& Farmer & 177 & 27.1 \\
& Daily labor & 26 & 4.0 \\
\hline Family monthly income & $\leq 1000$ & 141 & 21.7 \\
& $1001-1999$ & 132 & 20.3 \\
& $\geq 2000$ & 377 & 58.0 \\
\hline *: single and divorced, **: Muslim and protestant & & \\
\hline
\end{tabular}

Obstetrics related factors: From the total participants, $50.8 \%$ of the participants were prim-para. Among study participant, $22.2 \%$ had no history of antenatal follow up in their current delivery and $15.2 \%$ had no knowledge of danger signs of labor Among those who had a history of birth, $65.9 \%$ were given their most recent childbirth at a health facility (Table 2). 
Table 2

Obstetrics related factors for delay in making decision to seeking care on institutional delivery service among mothers who gave birth in South Gondar zone hospitals, Ethiopia, 2020.

\begin{tabular}{|c|c|c|c|}
\hline Variables & Categories & Frequency & Percent(\%) \\
\hline \multirow[t]{3}{*}{ Gravida } & Prim gravida & 330 & 50.8 \\
\hline & Multigravida & 194 & 29.8 \\
\hline & Grand multigravida & 126 & 19.4 \\
\hline \multirow[t]{3}{*}{ Parity } & 1 & 315 & 48.5 \\
\hline & $2-4$ & 208 & 31.5 \\
\hline & $>=5$ & 130 & 20.0 \\
\hline \multirow[t]{2}{*}{ ANC visits } & yes & 506 & 77.8 \\
\hline & no & 144 & 22.2 \\
\hline \multirow[t]{2}{*}{ Planned pregnancy } & Yes & 242 & 37.2 \\
\hline & No & 408 & 62.8 \\
\hline \multirow[t]{2}{*}{ Wanted pregnancy } & Yes & 621 & 95.5 \\
\hline & No & 29 & 4.5 \\
\hline \multirow{2}{*}{ Previous home delivery $(n=347)$} & Yes & 171 & 49.29 \\
\hline & No & 176 & 50.71 \\
\hline \multirow[t]{2}{*}{ Readiness to deliver in the health institution } & Yes & 527 & 81.1 \\
\hline & No & 123 & 18.9 \\
\hline \multirow{2}{*}{$\begin{array}{l}\text { Knowledge of danger signs of labor (at } \\
\text { least one) }\end{array}$} & Yes & 551 & 84.8 \\
\hline & No & 99 & 15.2 \\
\hline \multirow[t]{2}{*}{ Pregnancy outcome } & Livebirth & 615 & 94.6 \\
\hline & Stillbirth & 35 & 5.4 \\
\hline \multirow[t]{2}{*}{ Time of labor onset } & Day & 392 & 60.7 \\
\hline & Night & 258 & 39.3 \\
\hline \multirow[t]{3}{*}{ Birth weight of the baby } & $<2500 \mathrm{~g}$ & 76 & 11.7 \\
\hline & $2500-4000 \mathrm{~g}$ & 556 & 85.5 \\
\hline & $\geq 4000 \mathrm{~g}$ & 18 & 2.8 \\
\hline
\end{tabular}




\begin{tabular}{|llll|}
\hline Variables & Categories & Frequency & Percent(\%) \\
\hline Number of children & one & 328 & 50.5 \\
& $2-4$ children & 268 & 41.2 \\
& $\geq 5$ children & 54 & 8.3 \\
\hline Mode of delivery in the past $(n=322)$ & SVD & 282 & 87.6 \\
& Instrumental delivery & 10 & 3.1 \\
& CS & 30 & 9.3 \\
\hline The current mode of delivery & SVD & 546 & 84.0 \\
& Instrumental delivery & 41 & 6.3 \\
\hline The complication of after delivery & C/s & 63 & 9.7 \\
\hline & Yes & 57 & 8.8 \\
\hline
\end{tabular}

Health facility related factors: In this study, $87(13.4 \%)$ of the participants had no health facility in the Keble, and 415(63.8\%) greater than five kilometers from home to health facility (Table 3).

Table 3

Health facility factors for delay in making decision to seeking care on institutional delivery service among mothers who gave birth in South Gondar zone hospitals, Ethiopia, 2020

\begin{tabular}{|llll|}
\hline Variables & Categories & frequency & percent\% \\
\hline The health facility in the Keble & Yes & 563 & 86.6 \\
\hline $\begin{array}{l}\text { Public transport service in your area go to the health } \\
\text { facility }\end{array}$ & Yes & 87 & 13.4 \\
\hline The distance from home to health institution & No & 129 & 80.2 \\
& $<5 \mathrm{~km}$ & 235 & 19.8 \\
\hline Referred from other health facilities & $\geq 5 \mathrm{~km}$ & 415 & 36.2 \\
& Yes & 205 & 63.8 \\
\hline Mode of transportation & No & 445 & 68.5 \\
\hline & Foot & 411 & 63.2 \\
\hline
\end{tabular}


Factors of delay in making decision to seeking care on institutional delivery: Bi-variate analysis was done to assess any relation between independent variables and delay in making decision to seeking care on institutional delivery. In bivariate analysis, residence, education status of the mothers, occupation status of the mothers, ANC visit, planned of pregnancy, number of children, time of labor onset, the distance from home to health institution, and the health facility in the Keble were considered statistically significant with delay in making decision to seeking care on institutional delivery. Multi-variable logistic regression analysis showed that participants who reside in rural area were 3.14 times more likely delay in making decision to seeking care on institutional delivery than who lives in urban (AOR $=3.14,95 \%$, $\mathrm{Cl}: 2.40-4.01)$. Likewise, respondents uneducated mothers were 3.62 times more likely delay in making decision to seeking care on institutional delivery than those who did educated mothers (AOR $=3.62,95 \%$, $\mathrm{Cl}: 2.45-5.52)$, Respondents who had no planned of pregnancy were 2.01 times more likely delay in delay in making decision to seeking care on institutional delivery than those who had planned pregnancy (AOR: 2.01, 95\% Cl: 1.84-7.96), and those who had no health facilities in Keble were 1.62 times more likely delay in making decision to seeking care on institutional delivery than who had health facilities in Keble (AOR: 1.62, 95\% Cl: 1.43-6.32) (Table 4). 
Table 4

Factors associated with delay in making decision to seeking care on institutional delivery among mothers who gave birth in South Gondar zone hospitals, Ethiopia, 2020

\begin{tabular}{|c|c|c|c|c|c|}
\hline \multirow[t]{2}{*}{ Variables } & \multicolumn{3}{|c|}{$\begin{array}{l}\text { Delay in making decision to } \\
\text { seeking care }\end{array}$} & \multirow[t]{2}{*}{$\operatorname{COR}(95 \% \mathrm{Cl})$} & \multirow[t]{2}{*}{ AOR(95\%Cl) } \\
\hline & Categories & Yes & No & & \\
\hline \multirow[t]{2}{*}{ Residence } & Urban & 61 & 163 & 1 & 1 \\
\hline & Rural & 251 & 175 & $3.83(3.19-7.82)$ & $\begin{array}{l}3.14(2.40- \\
4.01) \star \star\end{array}$ \\
\hline \multirow{2}{*}{$\begin{array}{l}\text { Education status of the } \\
\text { mothers }\end{array}$} & Educated & 192 & 267 & 1 & 1 \\
\hline & Uneducated & 147 & 44 & $4.65(3.79-8.56)$ & $\begin{array}{l}3.62(2.45- \\
5.52) \star \star\end{array}$ \\
\hline \multirow{2}{*}{$\begin{array}{l}\text { Occupation status of the } \\
\text { mothers }\end{array}$} & Employed & 104 & 232 & 1 & \\
\hline & Unemployed & 132 & 182 & $1.62(1.09-2.59)$ & \\
\hline \multirow[t]{2}{*}{ ANC visit } & & 100 & 272 & 1 & \\
\hline & & 136 & 142 & $2.61(1.54-4.39)$ & \\
\hline \multirow[t]{2}{*}{ Planned of pregnancy } & Yes & 220 & 172 & 1 & 1 \\
\hline & No & 54 & 13 & $3.24(1.72-6.14)$ & $\begin{array}{l}2.07(1.84- \\
7.96)^{*}\end{array}$ \\
\hline \multirow[t]{3}{*}{ Number of children } & one & 127 & 201 & 1 & \\
\hline & $2-4$ & 94 & 174 & $0.86(0.23-0.96)$ & \\
\hline & $\geq 5$ children & 15 & 39 & $0.61(0.53-0.81)$ & \\
\hline \multirow[t]{2}{*}{ Time of labor onset } & Day & 152 & 240 & 1 & \\
\hline & Night & 174 & 84 & $3.27(1.65-3.56)$ & \\
\hline \multirow{2}{*}{$\begin{array}{l}\text { The distance from home to } \\
\text { health institution }\end{array}$} & $<5 \mathrm{~km}$ & 79 & 1562 & 1 & \\
\hline & $\geq 5 \mathrm{~km}$ & 157 & 58 & $1.20(1.02-8.28)$ & \\
\hline \multirow{2}{*}{$\begin{array}{l}\text { The health facility in the } \\
\text { Keble }\end{array}$} & Yes & 13 & 74 & 1 & 1 \\
\hline & No & 223 & 340 & $8.68(2.68-10.65)$ & ${ }_{*}^{1.62(1.43-6.32)}$ \\
\hline
\end{tabular}

\section{Discussion}


In this study reveals that two hundred thirty-six $(36.3 \%)$ with $(95 \% \mathrm{Cl}=32.6$ to 40.1$)$ of interviewed case made a delay in making decision to seeking care on time for institutional delivery. This was consistent with a study conducted in Hadiya zone (40.1\%), [6]. However, delay in making decision to seeking care for institutional delivery was lower than other studies conducted in Dawuro zone42\%,[3]. The possible explanation might be due to the difference in the socio-cultural characteristics of the study participants and study designs.

On the other hand, the current study finding was higher as compared to the study conducted in Arsi zone [7], and North Showa [15] where $26.2 \%$ and $23.1 \%$ respectively. The possible reason might be due to a lack of awareness of mothers and the family as a whole for danger signs of pregnancy. Because $29.4 \%$ of the mothers and $21.5 \%$ of her husband are unable to read and write in this study. In addition to this, in the current study, $34.5 \%$ of informants were rural in residency and are living in poor socioeconomic status. This may affect their delivery service utilization and can contribute the proportion to be high. The other possible reason might be due to bad road construction, long distance of health institutions from their home, and lack of transportation. It might be also due to case overload. Lastly, it might be due to the lack of skill of health care providers and disrespectful service delivery system.

The current study demonstrated that rural residency was found to be a statistically significant predictor of the outcome variable. Those mothers who are living in a rural area were more than three times more likely prone to delay in making decision to seeking care for institutional delivery than those who are living in the Urban. This finding is supported by studies conducted in the Dawuro zone [3]. The possible reason might be due to lack of women empowerment for early decision-making autonomy, poor physical access to health facilities that provide safe delivery service, poor road construction, and lack of access to health education regarding complications that would happen during labor and delivery. Rural women are more commonly influenced by cultural norms. These restrictive socio-cultural norms may hurt the utilization of maternal health care services. On the contrary, urban women are more aware and accessed information concerning the benefits of health facility delivery through different media. So they are less likely to prone to delay in making decision to seeking care for institutional delivery.

The analysis also showed that uneducated mothers were more than 3.62 times more likely to be delayed as compared to that of educated mothers for institutional delivery.

The result of this study revealed that mothers who had unplanned pregnancy were 2.07 times more likely to be delay as compared to those who had planned pregnancy for institutional delivery.

Lastly, the study also suggested that mothers who had no health facilities in Keble were 1.62 times more likely to prone to delay in making decision to seeking care of institutional delivery than those having health facility in the Keble.

The possible explanation might be due to a similar study design and socio-demographic characteristics of study informants across each finding. 


\section{Conclusion}

One in three delivered mothers had been delayed in making decision to seek care in South Gondar zone at the time of study. Pregnant mothers living in the rural area, unplanned of pregnancy, uneducated mothers and health facilities in kebels. Therefore, strategies to identify determinants and reduced of delay in making decision to seek care.

\section{Article Of Summary}

\section{Strengths}

- Probability sampling technique were considered to be the strength of this study to generalize the findings to the study population.

- Conducting analyses using logistic regression model were considered to be the strength of this study because it shows the association between predicted and response variables.

- The model was considered to control the effect of confounders (the enemy of data) seeking to minimize introducing bias at the analysis stage

\section{Limitation}

- Information bias may occur because the data were collected from postpartum mothers and experiencing new life adjustment, and eager to get a discharge

\section{Abbreviations}

ANC: Ante-Natal Care

AOR: Adjusted Odds Ratio

C/S: Cesarean section

Cl: Confidence Interval

COR: Crude Odds Ratio

EmOC: Emergency Obstetric Care

IRB: Institutional Review Board

SD: Standard Deviation

SDG: Sustainable Development Goal

SPSS: Statistical Package for Social Science 


\section{Declarations}

\section{Ethics approval and consent to participate}

It was obtained from the Institutional Review Board (IRB) of the University of Gondar on behalf of the Ethical Review Committee of the school of midwifery. A letter of cooperation was obtained from the Amhara region health office. The reasons why the research to be done was explained to the study subjects, verbal informed consent was obtained from each study subject after explanation of the purpose of the study, and involvement (to be a participant) was after their complete consent. Due to the approval of ethical committee that the research did not adversely affect the rights and welfare of the participants. Any women who were not willing to participate in the study were not forced to participate, no personal identifications were included in the datasheet and all data taken from the participants were kept strictly confidential and used only for the study purpose.

\section{Consent for publication}

Not applicable

\section{Availability of data and materials}

The dataset analyzed during the current study available from the corresponding author on reasonable request.

\section{Competing interests}

The authors have declared that they have no competing interests.

\section{Funding}

It was financially supported by University of Gondar.

\section{Authors' contribution}

GA wrote the proposal, participated in data collection. GA, DT, BG and KA analyzed the data, drafted the paper, and prepared the manuscript, approved it with few revisions, participated in data analysis, and revised subsequent drafts of the paper. All the authors read and approved the final manuscript sent for publication.

\section{Acknowledgments}

The authors are thankful to the University of Gondar that give the opportunity and Amhara region health office who gave us a supportive letter. We would also like to direct our thanks to the study participants for 
their permission and cooperation to participate in this study. We also thank our data collectors and supervisor.

\section{References}

1. Roy, M.P., Factors determining institutional delivery in rural India. Medical Journal of Dr. DY Patil Vidyapeeth, 2020. 13(1): p. 53.

2. Yarinbab, T.E. and S.G. Balcha, Delays in Utilization of Institutional Delivery Service and its Determinants in Yem Special Woreda, Southwest Ethiopia: Health Institution Based Cross Sectional Study. 2018.

3. Dodicho, T., Delay in Making Decision to Seek Institutional Delivery Service Utilization and Associated Factors among Mothers Attending Public Health Facilities in Dawuro Zone, Southern Ethiopia. 2020.

4. Asare, E.A.M., Determinants of Utilisation of Maternal Health Care Services Among Pregnant Women in Kwahu South District. 2017, University Of Ghana.

5. Gabrysch, S. and O.M. Campbell, Still too far to walk: literature review of the determinants of delivery service use. BMC pregnancy and childbirth, 2009. 9(1): p. 34.

6. Lire, A., et al., Delays for utilizing institutional delivery and associated factors among mothers attending public health facility in Hadiya Zone, Southern Ethiopia. Science, 2017. 5(6): p. 149-157.

7. Amare, Y.W., et al., Factors associated with maternal delays in utilising emergency obstetric care in Arsi Zone, Ethiopia. South African Journal of Obstetrics and Gynaecology, 2019. 25(2): p. 56-63.

8. Berhan, Y. and A. Berhan, Commentary: reasons for persistently high maternal and perinatal mortalities in Ethiopia: part III-perspective of the "three delays" model. Ethiopian journal of health sciences, 2014. 24: p. 137-148.

9. Killewo, J., et al., Perceived delay in healthcare-seeking for episodes of serious illness and its implications for safe motherhood interventions in rural Bangladesh. Journal of health, population, and nutrition, 2006. 24(4): p. 403.

10. Thaddeus, S. and D. Maine, Too far to walk: maternal mortality in context. Social science \& medicine, 1994. 38(8): p. 1091-1110.

11. Pathak, P., et al., Factors Associated with the Utilization of Institutional Delivery Service among Mothers. Journal of Nepal Health Research Council, 2017. 15(3): p. 228-234.

12. Andargie, A.A. and M. Abebe, Factors associated with utilization of institutional delivery care and postnatal care services in Ethiopia. Journal of Public Health and Epidemiology, 2018. 10(4): p. 108122.

13. Win, T., P. Vapattanawong, and P. Vong-ek, Three delays related to maternal mortality in Myanmar: a case study from maternal death review, 2013. Journal of Health Research, 2015. 29(3): p. 179-187.

14. Yarinbab, T.E. and S.G. Balcha, Delays in utilization of institutional delivery service and its determinants in Yem Special Woreda, Southwest Ethiopia: health institution based cross-sectional study. J Gynecol Women's Health, 2018. 10(3): p. 555793. 
15. Abera, G., et al., Male partner role on reducing delay in decision to seek emergency obstetric care and associated factors among women admitted to maternity ward, in hospitals of North Showa, Amhara, Ethiopia. Gynecol Obstet, 2015. 5(01). 